\title{
Direct Percutaneous Embolization of a Lymphocutaneous Fistula
}

\author{
Soumil Singhal ${ }^{1}$ Mangerira Chinnappa Uthappa ${ }^{1}$

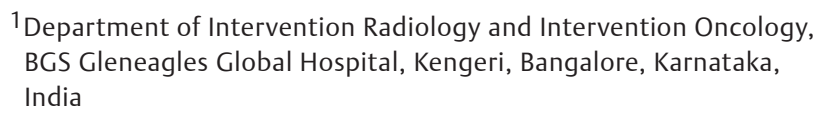

Address for correspondence Soumil Singhal, MD, Department of Intervention Radiology and Intervention Oncology, BGS Gleneagles Global Hospital, Kengeri, Bangalore 560060, Karnataka, India (e-mail: drsoumilsinghal75@gmail.com).

J Clin Interv Radiol ISVIR 2019;3:65-66

\section{Introduction}

Lymphocutaneous fistula is a rare clinical condition. It presents both a diagnostic and a therapeutic challenge. The condition is often missed or goes undiagnosed. It is associated with reduced quality of life. We report a case of secondary lymphocutaneous fistula that was undiagnosed and left untreated on several occasions but was successfully treated with direct percutaneous embolization.

\section{Case Report}

An 83-year-old male patient presented to us with complaints of a wound in the right groin since the past 4 months. The wound was associated with a discharge of a clear and odorless fluid with soakage of approximately 8 to 10 dressing pads per day. These complaints were also associated with weight loss $(\sim 6-8 \mathrm{~kg})$, social anxiety, limited and reduced social interaction, and depression. This was, however, not associated with fever, pain, or blood-tinged discharge. The patient gave a past history of undergoing an incision and drainage procedure for a swelling in the right groin about 4 months back following which the patient developed this wound. Initially, the wound was managed conservatively by reassuring the patient. On the persistence of the complaint, the treating surgeon first attempted compression dressings and a few days later tried negative-pressure dressings both of which did not resolve the condition. The patient and his family did some research on this disease and with a probable diagnosis of a lymphocutaneous fistula in mind approached our interventional radiology team through the Internet.

received

December 6, 2018 accepted after revision

January 2, 2019

published online

March 18, 2019
On clinical evaluation, a $1 \times 0.5-\mathrm{cm}$ wound was noted in the right thigh approximately $3 \mathrm{~cm}$ below the right groin margin. The wound had an excoriated margin and was associated with a serous discharge. On ultrasound examination, a small $1.1 \times 3.3-\mathrm{cm}$ hypoechoic focus with internal echoes was seen in the area of concern with a tract extending up to the external wound ( $\boldsymbol{- \text { Fig. }} \mathbf{1}$ ). The focus was seen adjacent to the superficial inguinal lymph node. A direct percutaneous embolization was planned. Under fluoroscopic and ultrasound guidance, a $24 \mathrm{G}$ needle was placed in the center of the hypoechoic focus, and $10 \mathrm{cc}$ of Lipiodol (Iodinated glycerol ester, Lipiodol Ultra-Fluid, Guerbet $\mathrm{GmbH}$ ) was injected followed by a saline flush. The lymphatic system was well-delineated post Lipiodol injection ( - Fig. 2). The needle was withdrawn, and a tight compression bandage was applied at the site of the wound. A follow-up was performed at 4 weeks, which showed sealing of the external wound with no discharge from the site post-procedure ( - Fig. $\mathbf{3}$ ).

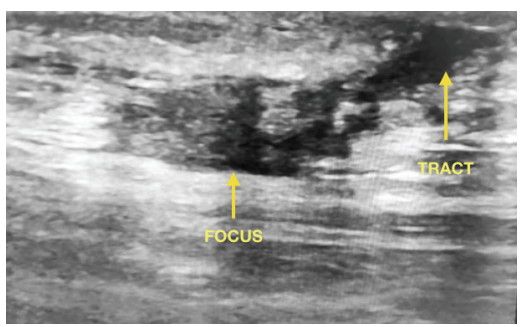

Fig. 1 A small $1.1 \times 3.3-\mathrm{cm}$ hypoechoic focus (arrow) with internal echoes is seen with a tract (arrow) extending up to the external wound.
License terms

(이 (1) $\odot$ 10.1055/s-0039-1681121 ISSN 2457-0214. 


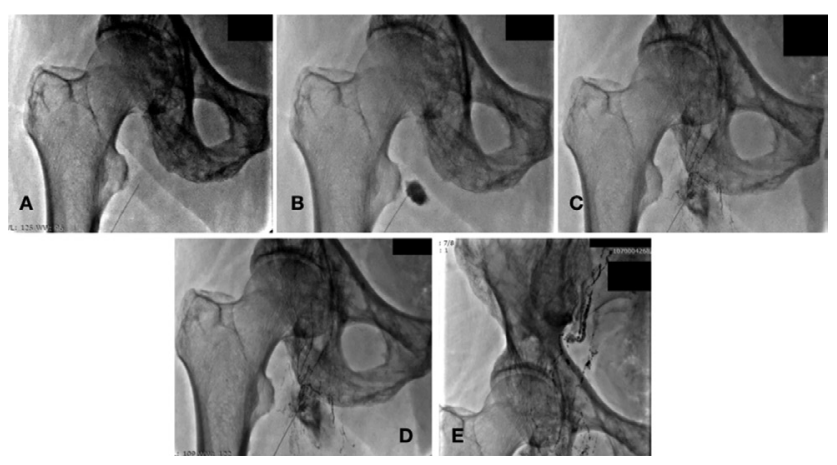

Fig. 2 (A-E) Angiographic images showing serial phases following local injection of Lipidol within the focus with visualization of right-sided lymphatic system.

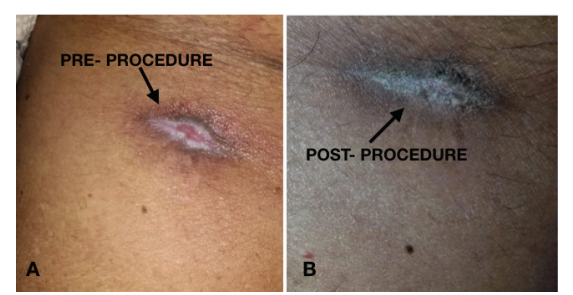

Fig. 3 (A, B) Pre- and post-procedure wound status. (B) shows a healed wound compared with (A).

\section{Discussion}

Lymphocutaneous fistulas can be primary or secondary. Secondary lymphocutaneous fistulas occur due to surgery or interventional procedures. The incidence of the condition ranges between 0.5 and $6 \% .{ }^{1-4}$ In the past, lymphoscintigraphy and intraoperative dye injection have been used to delineate the anatomy and site of leak. Lohrmann et al reported the advantage of magnetic resonance lymphangiography in their series of four patients with lymphocutaneous fistula. ${ }^{5}$ Lymphangiography has been reported as an effective treatment option in patients with lymphatic leakage.6.7 Kos et al reported an occlusion of $73.3 \%$ in patients with secondary lymphatic leakage following lymphangiography. ${ }^{7}$
The review of literature has shown only one case report of a patient treated by intervention for a similar complaint of lymphocutaneous fistula. ${ }^{8}$

\section{Conclusion}

Early diagnosis and intervention for lymphocutaneous fistula are very important. Lymphangiography with Lipiodol can be both diagnostic and therapeutic. This intervention is safe, very effective, and can be repeated if required.

\section{Conflict of Interest}

None.

\section{References}

1 Tyndall SH, Shepard AD, Wilczewski JM, Reddy DJ, Elliott JP Jr, Ernst CB. Groin lymphatic complications after arterial reconstruction. J Vasc Surg 1994;19(5):858-863, discussion 863-864

2 Croft RJ. Lymphatic fistula: a complication of arterial surgery. BMJ 1978;2(6131):205

3 Scharff RP, Recto MR, Austin EH III, Wilkerson SA. Lymphocutaneous fistula as a long-term complication of multiple central venous catheter placement. Tex Heart Inst J 2000;27(1):57-60

4 Mayer R, Sminia P, McBride WH, et al. Lymphatic fistulas: obliteration by low-dose radiotherapy. Strahlenther Onkol 2005;181(10):660-664

5 Lohrmann C, Felmerer G, Foeldi E, Bartholomä J-P, Langer M. MR lymphangiography for the assessment of the lymphatic system in patients undergoing microsurgical reconstructions of lymphatic vessels. Microvasc Res 2008;76(1):42-45

6 Matsumoto T, Yamagami T, Kato T, et al. The effectiveness of lymphangiography as a treatment method for various chyle leakages. Br J Radiol 2009;82(976):286-290

7 Kos S, Haueisen H, Lachmund U, Roeren T. Lymphangiography: forgotten tool or rising star in the diagnosis and therapy of postoperative lymphatic vessel leakage. Cardiovasc Intervent Radiol 2007;30(5):968-973

8 Quencer KB, Ayyagari RR, Friedman T. Iatrogenic lymphocutaneous fistula secondary to right-sided pheresis catheter placement and its percutaneous treatment: a case report. J Vasc Access 2017;18(4):e45-e47 